Research Article

\title{
Kinetodynamic Model and Simplified Model of X-Type Seat System with an Integrated Spring Damper
}

\author{
Changcheng Zhou $\mathbb{D}^{1},{ }^{1}$ Leilei Zhao $\mathbb{D}^{\circ},{ }^{2}$ Yuewei Yu, ${ }^{1}$ Fuxing Yang, ${ }^{2}$ and Song Wang $\mathbb{D}^{2}$ \\ ${ }^{1}$ School of Transportation and Vehicle Engineering, Shandong University of Technology, 12 Zhangzhou Road, Zibo 255049, China \\ ${ }^{2}$ School of Automation, Beijing University of Posts and Telecommunications, 10 Xitucheng Road, Haidian District, \\ Beijing 100876, China \\ Correspondence should be addressed to Leilei Zhao; zhaoleilei611571@163.com
}

Received 3 April 2018; Revised 5 July 2018; Accepted 31 July 2018; Published 3 October 2018

Academic Editor: Nuno M. Maia

Copyright (C) 2018 Changcheng Zhou et al. This is an open access article distributed under the Creative Commons Attribution License, which permits unrestricted use, distribution, and reproduction in any medium, provided the original work is properly cited.

\begin{abstract}
A simplified analytical model with transformation coefficients of X-type seat system with an integrated spring damper for control strategies development is proposed on the basis of a kinetodynamic model. Firstly, based on a commercial seat of trucks, the relationship between the suspension support force and the spring force was created by using virtual work principle. The analytical formulae of the equivalent stiffness $K_{\mathrm{e}}$ and the stiffness transformation coefficient $\rho_{k}$ were deduced. Based on the principle of conservation of energy, the analytical formulae of the equivalent damping coefficient $C_{e}$ and the damping transformation coefficient $\rho_{c}$ were deduced. Then, the motion equation of the simplified model was created. Secondly, the nonlinear dynamic equation of a complex seat model including the kinematic characteristics was established. Thirdly, the road test was conducted using a heavy truck to collect the seat vibration signals. Finally, the simplified model was validated by the tested data and compared with the complex model. The results show that the accuracy of the simplified model is acceptable. Moreover, the influence laws of kinematic parameters on $\rho_{k}$ and $\rho_{c}$ were revealed. The proposed simplified model provides an accurate and efficient tool for designing controllable seat suspension system that minimizes a necessary tuning process.
\end{abstract}

\section{Introduction}

Trucks play an important role in transportation and logistics industry. As products of human civilization and technology progress, they have made great contributions to the social development [1]. Because of the complex and changeable road conditions, the vibration caused by the road excitation and the power assembly not only leads to the damage of the vehicle parts but also reduces the ride comfort [2]. More seriously, it damages the driver's physical and mental health and endangers the driving safety [3].

With the rapid development of the truck industry, improving ride comfort has become a major concern of modern truck designers [4-6]. The seat suspension system is an important part of modern trucks [7]. The seat suspension system directly affects the NVH (noise, vibration, and harshness) performance [8]. Thus, it becomes a key link to improve ride comfort of trucks [9].
The seat suspension system can be mainly divided into three categories: passive seat suspensions [10], semiactive seat suspensions [11], and active seat suspensions [12]. The vibration isolation capability of passive seat suspensions is limited. In order to improve drivers' ride comfort as much as possible, the controllable seat suspension is becoming a research hotspot [13].

The development and implementation of most of the control strategies depend on the dynamic model of the seat suspension system. Thus, the dynamic model of the seat suspension system is an important foundation for control strategies development and electric control. To facilitate control strategies development, the seat dynamic model should be simplified as much as possible under the premise of meeting the model accuracy. Generally speaking, it is necessary to compromise the model accuracy and the solution time.

The existing dynamic models considering the seat suspension structure are mainly used for the vibration 
characteristics analysis. For example, Feng and $\mathrm{Hu}$ optimized the vibration acceleration transmissibility for seat suspension system with a parallel mechanism [14]. Wang et al. made a hierarchical optimization for scissor seat suspension [15]. Shangguan et al. optimized vehicle-specific seat suspension systems using a seat kinetodynamic model [16]. These complex models are useful for analyzing the internal and fundamental characteristics of seat mechanisms. They also benefit parameter analysis and optimization. However, from the point of view of controller design, their equations of motion are of no practical use because they cannot satisfy the real-timeliness for control strategies realization in practical engineering.

In most cases, the classical single DOF (degree of freedom) model of seat suspension system is used for control strategies development. The model is composed of one lumped mass, a linear spring, and a damper $[17,18]$. In recent years, scholars have carried out related research on controllable seat suspensions based on the classical single DOF model. Moreover, some fruitful research results have been achieved. Do et al. designed a new adaptive fuzzy sliding-mode controller to control a seat suspension [19]. Ning et al. researched an active seat suspension based on the Takagi-Sugeno fuzzy control [20]. Rajendiran et al. simulated the responses of seat suspension with PID and fuzzy logic controllers [21]. Ning et al. designed an active seat suspension for vibration control of heavy-duty vehicles [22]. Although the classical single DOF model can be used for exploring various kinds of control strategies, it does not establish the relationship between the model equivalent parameters and the suspension structure. Thus, it cannot be directly used in the design of the seat suspension controller for actual vehicles [23, 24]. Actually, the seat suspension kinematic mechanism and the layout form have great influences on the dynamic responses of the seat system $[25,26]$. Zhang and Zhao researched the nonlinear stiffness and vibration isolation characteristics of scissor-like structure with full types [27]; however, they did not provide the analytical formula of the equivalent damping coefficient of the seat damper. Available studies provide useful references for the design, control, and modeling of seat suspension system. However, there are few studies on providing an accurate simple model of seat suspension system with complex scissor mechanisms for control strategies development. Creating a simple seat model with reasonable accuracy is the primary motivation of this paper.

To facilitate control strategies development, this paper proposed a simplified analytical dynamic model with transformation coefficients of seat suspension system. In Section 2, according to a commercial seat of trucks, the nonlinear relationship between the suspension support force $F_{\mathrm{e}}$ and the spring force $F_{\mathrm{s}}$ was created by using virtual work principle. Based on the relationship, the analytical formula of the equivalent stiffness $K_{\mathrm{e}}$ and the stiffness transformation coefficient $\rho_{k}$ was deduced. Based on the principle of conservation of energy, the analytical formula of the equivalent damping coefficient $C_{\mathrm{e}}$ was deduced, and the damping transformation coefficient $\rho_{c}$ was proposed.
The motion equation of the simplified model was created. In Section 3, to facilitate comparison, the nonlinear dynamic equation of the seat kinetodynamic model is established by using Lagrange modeling method. In Section 4 , the simplified model was validated by the tested data and compared with the kinetodynamic model. In Section 5, the influence laws of kinematic parameters on $\rho_{k}$ and $\rho_{c}$ were revealed.

\section{Development of a Simplified Analytical Model of Seat Suspension System}

2.1. Physical Structure and Model of the Seat Suspension System. The seat suspension with an integrated spring damper has been gradually applied in trucks in recent years because of its compact structure [28]. The integrated spring damper is composed of a hydraulic damper, a spiral spring, and two bushings. The hydraulic damper and the spiral spring are connected in parallel. On the basis of the physical structure of X-type seat, the kinetodynamic model is created as shown in Figure 1(a). The moving parts contains seven rigids: the damper rod, the damper tube, the guide wheel at point $\mathrm{P}$, the guide wheel at point $\mathrm{R}$, the seat pan, the linkage PS, and the linkage OR. The coordinate system is shown in Figure 1(a) and its origin is at $S$ point. In the model, the lengths of the linkages RQ and PS are equal, so denote as $L$. For simplicity, denote the lengths of AS, BR, and BQ as $a, b$, and $c$, respectively. The lengths $a$ and $c$ are called as the lower installation distance and the upper installation distance, respectively. The angle between the linkage PS and the seat floor is $\theta$. Table 1 shows the topological relations among moving parts. This kinetodynamic model is rather complex, and it is inconvenient for control strategies development of the seat suspension. Thus, in Figure 1(b) a simplified analytical model with single DOF is proposed, which includes three parameters: $m$ is the effective mass of the driver body and the seat pan supported by the seat suspension, $K_{\mathrm{e}}$ is the vertical equivalent stiffness of the seat suspension, $C_{e}$ is the vertical equivalent damping coefficient of the seat suspension. For conveniently translating the complex model to the simplified DOF model, the key problem is how to obtain the analytical formulae of $K_{\mathrm{e}}$ and $C_{\mathrm{e}}$. In the following, the kinetodynamic model is denoted as the complex model. The simplified model is the equivalent model.

2.2. The Analytical Formula of the Equivalent Stiffness $K_{\mathrm{e}}$. If the seat pan produces an upward displacement $u$ from the static equilibrium position and $q=0$, the point $\mathrm{P}_{0}$ moves to the new point $\mathrm{P}$. In this condition, $u=z-q=z$. Thus, $u$ is defined as the vertical deformation of the seat suspension system. According to the geometric relationship, $u$ can be expressed as

$$
u=z_{\mathrm{P}}-z_{\mathrm{P} 0}
$$

Substituting $z_{\mathrm{P}}=L \sin \theta$ and $z_{\mathrm{P} 0}=L \sin \theta_{0}$ in Equation (1), we obtain the following: 


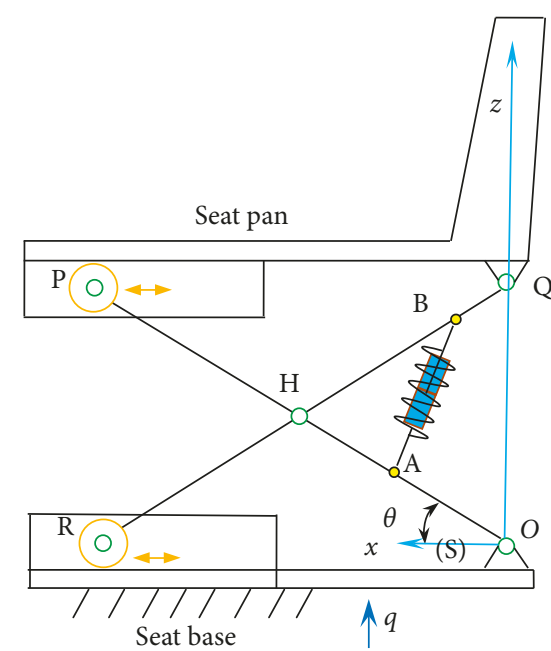

(a)

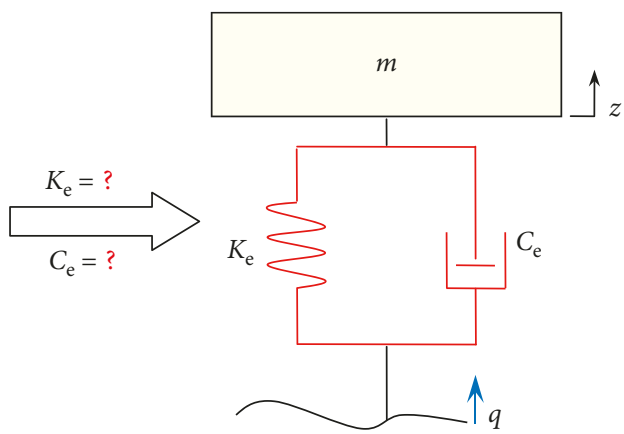

(b)

Figure 1: The vibration model: (a) the complex model and (b) the simplified model.

TABLE 1: The topological relations among moving parts.

\begin{tabular}{lcc}
\hline & Parts & Motion pair \\
\hline Damper rod & Damper tube & Translation pair \\
Damper rod & Linkage RQ & Revolute pair \\
Damper tube & Linkage PS & Revolute pair \\
Linkage RQ & Linkage PS & Revolute pair \\
Guide wheel at P & Seat pan & Translation pair \\
Guide wheel at R & Seat floor & Translation pair \\
Guide wheel at P & Linkage PS & Revolute pair \\
Linkage PS & Seat floor & Revolute pair \\
Linkage RQ & Seat pan & Revolute pair \\
Guide wheel at R & Linkage RQ & Revolute pair \\
\hline
\end{tabular}

$$
L \sin \theta-L \sin \theta_{0}=u \text {. }
$$

From Equation (2), we obtain the following:

$$
\sin \theta_{0}+\frac{u}{L}=\sin \theta
$$

At the static equilibrium position, the distance $l_{0}$ between the spring installation points can be expressed as

$$
l_{0}=\left[\left(x_{\mathrm{A} 0}-x_{\mathrm{B} 0}\right)^{2}+\left(z_{\mathrm{A} 0}-z_{\mathrm{B} 0}\right)^{2}\right]^{1 / 2} .
$$

Substituting $x_{\mathrm{A} 0}=a \cos \theta_{0}, z_{\mathrm{A} 0}=a \sin \theta_{0}, x_{\mathrm{B} 0}=c \cos \theta_{0}$, and $z_{\mathrm{B} 0}=b \sin \theta_{0}$ in Equation (4), we obtain the following:

$$
l_{0}=\left[(a-c)^{2} \cos ^{2} \theta_{0}+(a-b)^{2} \sin ^{2} \theta_{0}\right]^{1 / 2} \text {. }
$$

Let $X=(a-c)^{2}, \quad Y=(a-b)^{2}$, and $\eta=\sin \theta_{0}$, and Equation (5) can be expressed as

$$
l_{0}=\left[X\left(1-\eta^{2}\right)+Y \eta^{2}\right]^{1 / 2}
$$

When the spring is deformed from the static equilibrium position, the distance $l$ between the spring installation points can be expressed as

$$
l=\left[\left(x_{\mathrm{A}}-x_{\mathrm{B}}\right)^{2}+\left(z_{\mathrm{A}}-z_{\mathrm{B}}\right)^{2}\right]^{1 / 2} .
$$

Substituting $x_{\mathrm{A}}=a \cos \theta, x_{\mathrm{B}}=c \cos \theta, z_{\mathrm{A}}=a \sin \theta+q$, and $z_{\mathrm{B}}=b \sin \theta+q$ in Equation (7), we obtain the following:

$$
\begin{aligned}
l & =\left[(a-c)^{2} \cos ^{2} \theta+(a-b)^{2} \sin ^{2} \theta\right]^{1 / 2} \\
& =\left((a-c)^{2}\left[1-\left(\sin \theta_{0}+\frac{u}{L}\right)^{2}\right]+(a-b)^{2}\left(\sin \theta_{0}+\frac{u}{L}\right)^{2}\right)^{1 / 2} .
\end{aligned}
$$

Equation (8) can be further expressed as

$$
l=\left(X\left[1-\left(\eta+\frac{u}{L}\right)^{2}\right]+Y\left(\eta+\frac{u}{L}\right)^{2}\right)^{1 / 2}
$$

The deformation $\Delta l$ of the spring can be expressed as

$$
\begin{aligned}
\Delta l= & l-l_{0}=\left(X\left[1-\left(\eta+\frac{u}{L}\right)^{2}\right]+Y\left(\eta+\frac{u}{L}\right)^{2}\right)^{1 / 2} \\
& -\left[(a-c)^{2}\left(1-\eta^{2}\right)+(a-b)^{2} \eta^{2}\right]^{1 / 2} .
\end{aligned}
$$

According to the principle of virtual work, the following can be obtained:

$$
-F_{\mathrm{e}} \delta u+F_{\mathrm{s}} \delta(\Delta l)=0
$$

where $F_{\mathrm{e}}$ is the vertical external force acting on the seat pan, $F_{\mathrm{s}}$ is the spring force, and $\delta$ is the virtual displacement.

From Equation (10), $\delta(\Delta l)$ can be expressed as

$$
\begin{aligned}
\delta(\Delta l)= & \frac{1}{L}(Y-X)\left(\eta+\frac{u}{L}\right) \\
& \cdot\left(X\left[1-\left(\eta+\frac{u}{L}\right)^{2}\right]+Y\left(\eta+\frac{u}{L}\right)^{2}\right)^{-1 / 2} \delta u .
\end{aligned}
$$


Substituting Equation (12) in Equation (11), we obtain the following:

$$
F_{\mathrm{e}}=F_{\mathrm{s}} \frac{1}{L}[Y-X]\left(\eta+\frac{u}{L}\right)\left(X\left[1-\left(\eta+\frac{u}{L}\right)^{2}\right]+Y\left(\eta+\frac{u}{L}\right)^{2}\right)^{-1 / 2}
$$

Because the elastic element of the seat suspension is a spiral spring, thus, the spring force $F_{\mathrm{s}}$ can be expressed as

$$
F_{\mathrm{s}}=K_{\mathrm{s}}(\gamma-\Delta l) \text {, }
$$

where $\gamma$ is the precompression deformation of the spring and $K_{\mathrm{s}}$ is the spring stiffness.

Substituting Equation (14) in Equation (13), the force $F_{\mathrm{e}}$ can be further expressed as

$$
\begin{aligned}
F_{\mathrm{e}}= & K_{\mathrm{s}}(\gamma-\Delta l) \frac{1}{L}(Y-X) \\
& \cdot\left(\eta+\frac{u}{L}\right)\left(X\left[1-\left(\eta+\frac{u}{L}\right)^{2}\right]+Y\left(\eta+\frac{u}{L}\right)^{2}\right)^{-1 / 2} .
\end{aligned}
$$

The vertical equivalent stiffness $K_{\mathrm{e}}$ of the seat suspension can be solved by

$$
K_{\mathrm{e}}=\frac{d F_{\mathrm{n}}}{d u}=\frac{d\left[-F_{\mathrm{e}}+\left(m_{\mathrm{b}}+m_{0}\right) g\right]}{d u},
$$

where $F_{\mathrm{n}}$ is the vertical elastic restoring force of the seat suspension and $F_{\mathrm{n}}=F_{\mathrm{e}}+\left(-F_{\mathrm{e}}+\left(m_{\mathrm{b}}+m_{0}\right) g\right), m_{\mathrm{e}}$ is the effective mass of the driver body supported by the seat suspension, and $m_{0}$ is the effective mass of the seat pan supported by the seat suspension.

According to Equations (15) and (16), $K_{\mathrm{e}}$ can be expressed as

$$
K_{\mathrm{e}}=\rho_{k} K_{s},
$$

where the stiffness transformation coefficient $\rho_{k}$ can be expressed as

$$
\begin{aligned}
\rho_{k}= & -\left(\frac{m g L l_{0}^{2}}{\eta K_{s}(Y-X)}-\Delta l\right) \frac{(Y-X)}{L^{2} l} \\
& \cdot\left[1-\frac{1}{l}(Y-X)\left(\eta+\frac{u}{L}\right)^{2}\left(\frac{1}{l}+\frac{1}{\gamma-\Delta l}\right)\right] .
\end{aligned}
$$

In addition, at the static equilibrium position, let $F_{\mathrm{e}}=m g$. That is

$$
F_{\mathrm{e}}=m \mathrm{~g}=\left(m_{\mathrm{b}}+m_{0}\right) \mathrm{g} .
$$

According to Equations (15) and (19) and $u=0$, we obtain the following:

$$
K_{\mathrm{s}} \gamma \frac{\eta}{L}(Y-X)\left[X\left(1-\eta^{2}\right)+Y \eta^{2}\right]^{-1 / 2}=m \mathrm{~g}
$$

From Equation (20), at the static equilibrium position, the precompression deformation $\gamma$ can be determined by

$$
\gamma=\frac{m g L\left[X\left(1-\eta^{2}\right)+Y \eta^{2}\right]^{1 / 2}}{\eta K_{s}(Y-X)}=\frac{m g L l_{0}}{\eta K_{s}(Y-X)} .
$$

2.3. The Analytical Formula of the Equivalent Damping Coefficient $C_{\mathrm{e}}$. According to the conservation of energy, the energy dissipated by the damper in simplified model is equal to that in the kinetodynamic model. Thus,

$$
\frac{1}{2} C_{\mathrm{e}}\left(\frac{d u}{d t}\right)^{2}=\frac{1}{2} C_{\mathrm{d}}\left(\frac{d \Delta l}{d t}\right)^{2},
$$

where $C_{\mathrm{d}}$ is the damper damping.

According to the chain derivation rule, Equation (22) can be expressed as

$$
\frac{1}{2} C_{\mathrm{e}}\left(\frac{d u}{d t}\right)^{2}=\frac{1}{2} C_{\mathrm{d}}\left(\frac{d \Delta l}{d u} \cdot \frac{d u}{d t}\right)^{2}=\frac{1}{2} C_{\mathrm{d}}\left(\frac{d \Delta l}{d u}\right)^{2}\left(\frac{d u}{d t}\right)^{2} .
$$

From Equation (23), we obtain the following:

$$
C_{\mathrm{e}}=C_{\mathrm{d}}\left(\frac{d \Delta l}{d u}\right)^{2}
$$

From Equation (10), $d \Delta l / d u$ can be expressed as

$$
\begin{aligned}
\frac{\mathrm{d} \Delta l}{\mathrm{~d} u}= & \frac{1}{L}[Y-X]\left(\eta+\frac{u}{L}\right) \\
& \cdot\left(X\left[1-\left(\eta+\frac{u}{L}\right)^{2}\right]+Y\left(\eta+\frac{u}{L}\right)^{2}\right)^{-1 / 2} .
\end{aligned}
$$

Substituting Equation (25) in Equation (24), the vertical equivalent damping coefficient $C_{\mathrm{e}}$ of the seat suspension can be expressed as

$$
C_{\mathrm{e}}=\rho_{c} C_{\mathrm{d}}
$$

where the damping transformation coefficient $\rho_{c}$ can be expressed as

$$
\rho_{c}=\frac{(1 / L(Y-X)(\eta+u / L))^{2}}{X\left[1-(\eta+u / L)^{2}\right]+Y(\eta+u / L)^{2}}
$$

2.4. The Motion Equation of the Simplified Model. Substituting $u=0$ in Equations (17) and (26), the vertical equivalent stiffness $K_{\mathrm{e}}$ and the vertical equivalent damping coefficient $C_{e}$ at the static equilibrium position can be obtained. They are denoted as $K_{\mathrm{e} 0}$ and $C_{\mathrm{e} 0}$, respectively. At the static equilibrium position, the stiffness transformation coefficient and the damping transformation coefficient are denoted as $\rho_{k 0}$ and $\rho_{c 0}$, respectively. Thus, $K_{\mathrm{e} 0}$ and $C_{\mathrm{e} 0}$ can be further, respectively, expressed as

$$
\begin{aligned}
& K_{\mathrm{e} 0}=\rho_{k 0} K_{\mathrm{s}}, \\
& C_{\mathrm{e} 0}=\rho_{c 0} C_{\mathrm{d}} .
\end{aligned}
$$

Using Newton's second law, the motion equation of the simplified model can be written as

$$
m \ddot{z}+\rho_{c 0} C_{\mathrm{d}}(\dot{z}-\dot{q})+\rho_{k 0} K_{s}(z-q)=0 .
$$




\section{Motion Equation of the Complex Model}

The vibration equation of the seat system is created using the Lagrange modeling method in the section. Under the input excitation $q$ of the seat floor, the angle variation is $\varphi$, which is designated as the generalized coordinate for the kinetodynamic model [28].

The Lagrange equation of the seat system can be expressed as

$$
\frac{d}{d t}\left(\frac{\partial T}{\partial \dot{\varphi}}\right)-\frac{\partial T}{\partial \varphi}+\frac{\partial V}{\partial \varphi}+\frac{\partial D}{\partial \dot{\varphi}}=0,
$$

where, $T, V$, and $D$ are the kinetic energy, the potential energy, and the dissipated energy of the seat system, respectively.

From (30), we obtain the nonlinear motion equation of the kinetodynamic model:

$$
\begin{aligned}
& m\left[\ddot{q}-\ddot{\varphi} L \cos \left(\theta_{0}-\varphi\right)-\dot{\varphi}^{2} L \sin \left(\theta_{0}-\varphi\right)\right]\left[-L \cos \left(\theta_{0}-\varphi\right)\right] \\
& +K\left\{\left[(a-c)^{2} \cos ^{2}\left(\theta_{0}-\varphi\right)+(a-b)^{2} \sin ^{2}\left(\theta_{0}-\varphi\right)\right]^{1 / 2}-l_{0}\right\} \\
& \cdot\left[(a-c)^{2} \cos ^{2}\left(\theta_{0}-\varphi\right)+(a-b)^{2} \sin ^{2}\left(\theta_{0}-\varphi\right)\right]^{-1 / 2} \\
& \cdot\left[(a-c)^{2} \cos \left(\theta_{0}-\varphi\right) \sin \left(\theta_{0}-\varphi\right)\right. \\
& \left.-(a-b)^{2} \sin \left(\theta_{0}-\varphi\right) \cos \left(\theta_{0}-\varphi\right)\right] \\
& +\frac{C_{\mathrm{d}}\left[(a-c)^{2}-(a-b)^{2}\right]^{2} \sin ^{2}\left(2 \theta_{0}-2 \varphi\right) \dot{\varphi}}{4\left[(a-c)^{2} \cos ^{2}\left(\theta_{0}-\varphi\right)+(a-b)^{2} \sin ^{2}\left(\theta_{0}-\varphi\right)\right]}=0 .
\end{aligned}
$$

\section{Model Validation and Comparison}

In order to verify the effectiveness of the simplified model, the numerical simulations and comparison of the vertical acceleration responses were carried out in this section. The parameters of the seat system are as shown in Table 2. The driver mass is $75 \mathrm{~kg}$.

4.1. Verification of Random Vibration Response. To obtain the vibration signals for simulation and validation, according to the national standard GB/T 4970-2009, the road test was carried out and the vibration signals were collected. Based on the complex model and the simplified model, the values of the seat pan vertical frequency-weighted RMS acceleration $a_{\mathrm{w}}$ were calculated using the measured seat base accelerations at different speeds as inputs. The calculated results are shown in Table 3 . In order to make it clear to observe the differences, a histogram is used to provide a comparison of the calculated results, as shown in Figure 2.
TABLE 2: The values of the seat pan vertical frequency-weighted RMS acceleration $a_{\mathrm{w}}$.

\begin{tabular}{lccc}
\hline Parameter & Value & Parameter & Value \\
\hline$L(\mathrm{~mm})$ & 380 & $\theta_{0}\left({ }^{\circ}\right)$ & 45 \\
$a(\mathrm{~mm})$ & 70 & $K_{\mathrm{s}}(\mathrm{N} / \mathrm{mm})$ & 24 \\
$c(\mathrm{~mm})$ & 20 & $C_{\mathrm{d}}(\mathrm{Ns} / \mathrm{m})$ & 951 \\
\hline
\end{tabular}

TABLE 3: The values of the seat pan vertical frequency-weighted RMS acceleration $a_{\mathrm{w}}$.

\begin{tabular}{lccc}
\hline Speed $\nu(\mathrm{km} / \mathrm{h})$ & $\begin{array}{c}\text { Tested } \\
\left(\mathrm{m} / \mathrm{s}^{2}\right)\end{array}$ & \multicolumn{2}{c}{ Simulated $\left(\mathrm{m} / \mathrm{s}^{2}\right)$} \\
& 0.37 & 0.35 & 0.35 \\
50 & 0.41 & 0.38 & 0.38 \\
60 & 0.45 & 0.42 & 0.42 \\
70 & 0.48 & 0.44 & 0.43 \\
80 & 0.50 & 0.46 & 0.45 \\
90
\end{tabular}

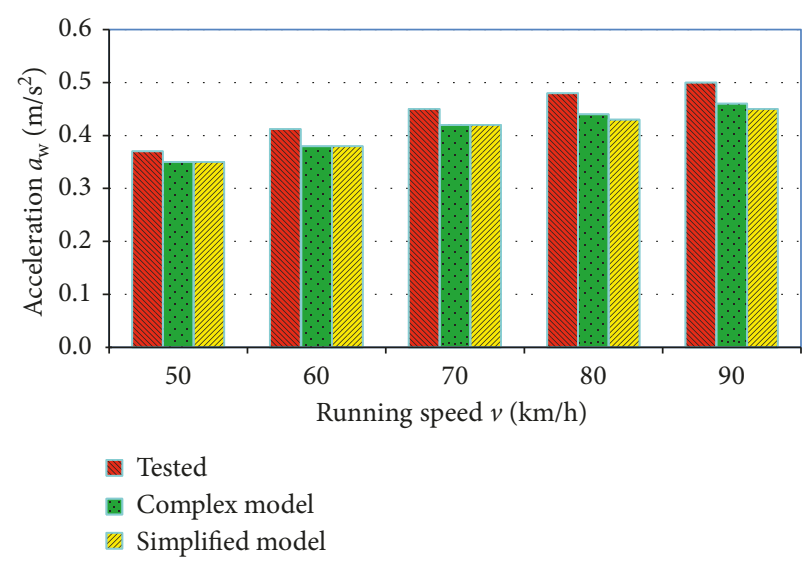

FIgURE 2: A comparison of the values of the seat pan vertical frequency-weighted RMS acceleration $a_{\mathrm{w}}$.

From Figure 2, it can be seen that the values of the seat pan vertical frequency-weighted RMS acceleration $a_{\mathrm{w}}$ calculated from the tested data are larger than those calculated from the simulated data based on the complex model and the simplified model. For the vehicle at lower speeds 50,60 , and $70 \mathrm{~km} / \mathrm{h}$, the values of $a_{\mathrm{w}}$ calculated from the complex model and the simplified model are the same, respectively. However, for the vehicle at higher speeds 80 and $90 \mathrm{~km} / \mathrm{h}$, the values of $a_{\mathrm{w}}$ calculated from the complex model are slightly larger than those from the simplified model. The maximum of the relative error between the simulated values of $a_{\mathrm{w}}$ calculated from the complex model and the tested data is $8.3 \%$. The maximum of the relative error between the simulated values of $a_{\mathrm{w}}$ calculated from the simplified model and the tested data is $10.4 \%$. The results show that the two models can reflect the random acceleration response of the seat pan, and the accuracy of the simplified model is slightly lower than that of the complex model. From the point of view of controller design, the accuracy of the simplified model 
can satisfy the control strategies realization in practical engineering.

\subsection{Verification and Comparison of the Vibration Transmissibility}

4.2.1. Verification of the Vibration Transmissibility. In this section, the transmissibility $T$ of the seat system was measured through the test of sine wave sweep. Before the test, the seat was fixed on the test bench. Moreover, the driver was replaced by a weight block with $55 \mathrm{~kg}$ which is calculated by $(8+75) \times 9.8 \times 0.73$. On the basis of the frequency sweep method, the transmissibility of the seat system was measured. In addition, the transmissibility of the complex model was calculated based on the frequency sweep method, and the transmissibility of the simplified model was analytically calculated using the transfer function from $q$ to $z$. A comparison of the transmissibility curves is shown in Figure 3. Based on Figure 3, the values of the natural frequency $f_{0}$ and the maximal transmissibility $T_{\max }$ were extracted. A comparison of the two characteristic parameters of the seat system is shown in Table 4.

From Figure 3, it can be seen that the simulation curves of the transmissibility $T$ coincides with that of the measured curve. There is a certain deviation in the frequency bands $0.5 \sim 1.5 \mathrm{~Hz}$ and $8.0 \sim 10.0 \mathrm{~Hz}$. The transmissibility curve calculated from the simplified model can reflect the real transmission characteristics of the seat suspension system. Table 4 shows that the tested $f_{0}$ is the same as the simulated $f_{0}$; the absolute deviation between the tested $T_{\max }$ and the simulated $T_{\max }$ is 0.01 , and the relative deviation is $1.0 \%$. The results further prove that the simplified model is effective. The main reason for the deviations is that the friction and gaps between the moving parts of the scissor mechanism are ignored in the simplified model.

4.2.2. Comparison of the Vibration Transmissibility Curves at Different Values of $m_{\mathrm{b}}$. Figure 4 provides a comparison of the vibration transmissibility curves at different values of $m_{\mathrm{b}}$ with the static equilibrium position unchanged. Where $m_{\mathrm{b}}=55,65,75$, and $85 \mathrm{~kg}$. From Figure 4, it can be seen that the transmissibility curves calculated from the simplified model are in good agreement with those calculated from the complex model at different values of $m_{\mathrm{b}}$. Moreover, as the value of the mass $m_{\mathrm{b}}$ increases, the natural frequency $f_{0}$ decreases, however, the maximal transmissibility $T_{\max }$ increases.

4.3. Comparison of Harmonic Response. The vibration response analysis of the seat system under harmonic excitation is one of the effective methods to investigate the differences of the models and the real system. Figure 5 provides a comparison of the seat pan acceleration responses for the seat system under harmonic excitations with the amplitude $A_{0}=10 \mathrm{~mm}$ and the excitation frequency $f=1.0$ and $2.0 \mathrm{~Hz}$.

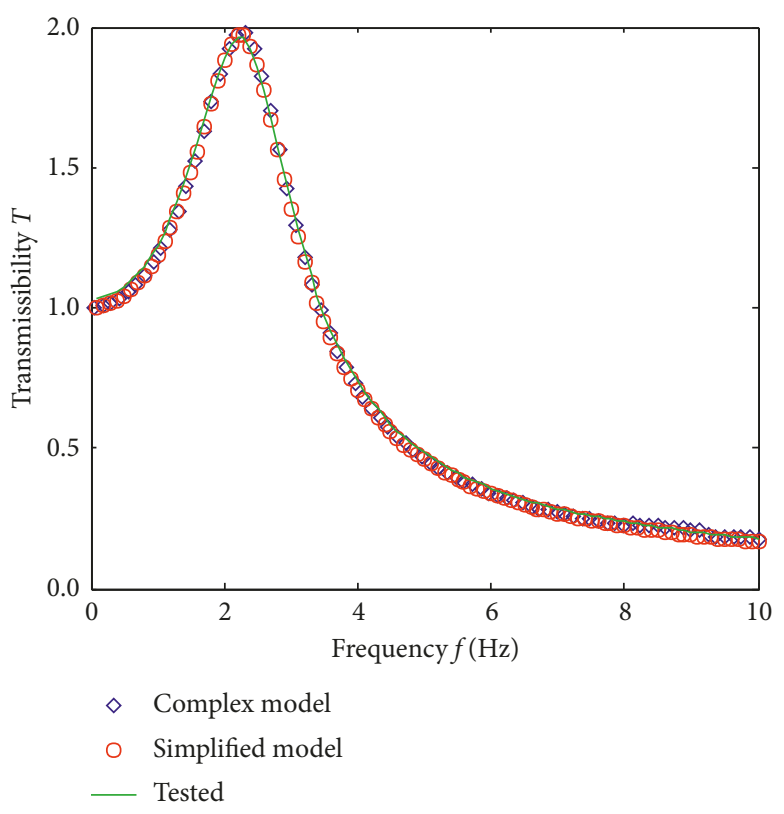

Figure 3: A comparison of the transmissibility curves.

TABLE 4: A comparison of the characteristic parameters of the seat system.

\begin{tabular}{lccc}
\hline $\begin{array}{l}\text { Characteristic } \\
\text { parameter }\end{array}$ & Tested & $\begin{array}{c}c \\
\text { Complex } \\
\text { model }\end{array}$ & $\begin{array}{c}\text { Simplified } \\
\text { model }\end{array}$ \\
\hline $\begin{array}{l}\text { Natural frequency } f_{0} \\
\text { Maximal transmissibility } T_{\max }\end{array}$ & 2.2 & 2.2 & 2.2 \\
\hline
\end{tabular}

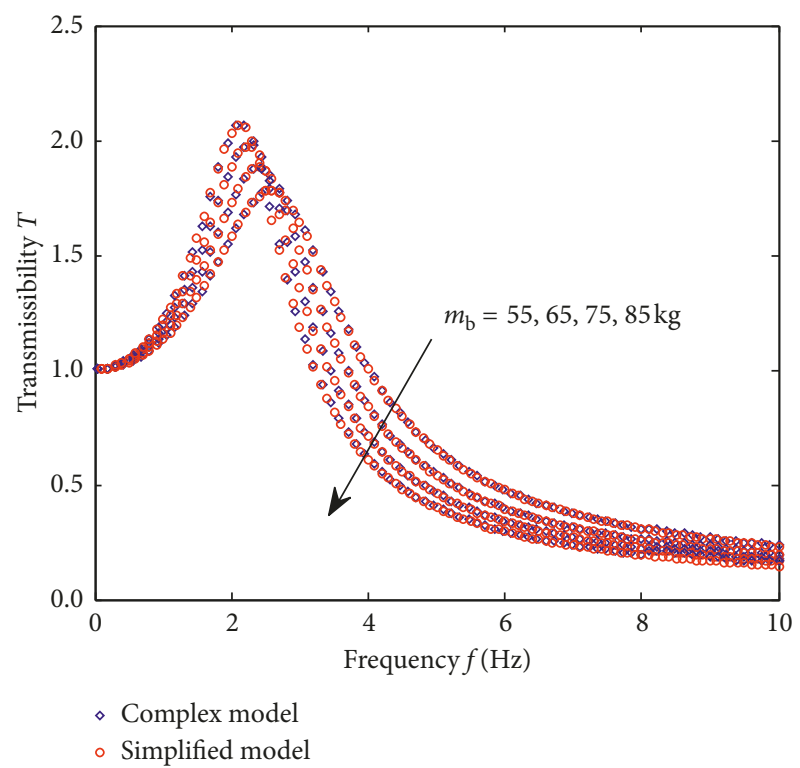

FIgURE 4: A comparison of the vibration transmissibility curves at different values of $m_{\mathrm{b}}$.

From Figure 5, it can be seen that the simplified model can be considered suitable for reproducing the real seat acceleration response. 


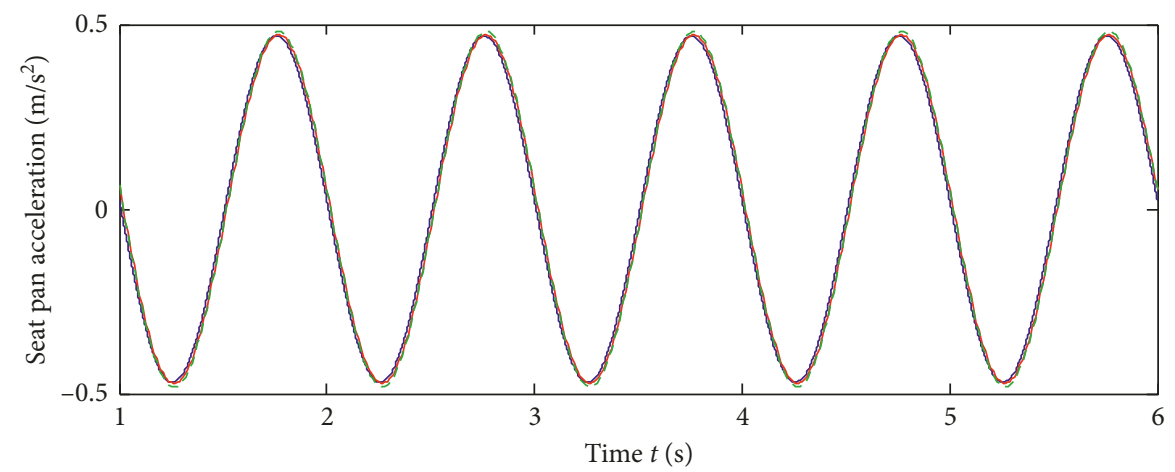

(a)

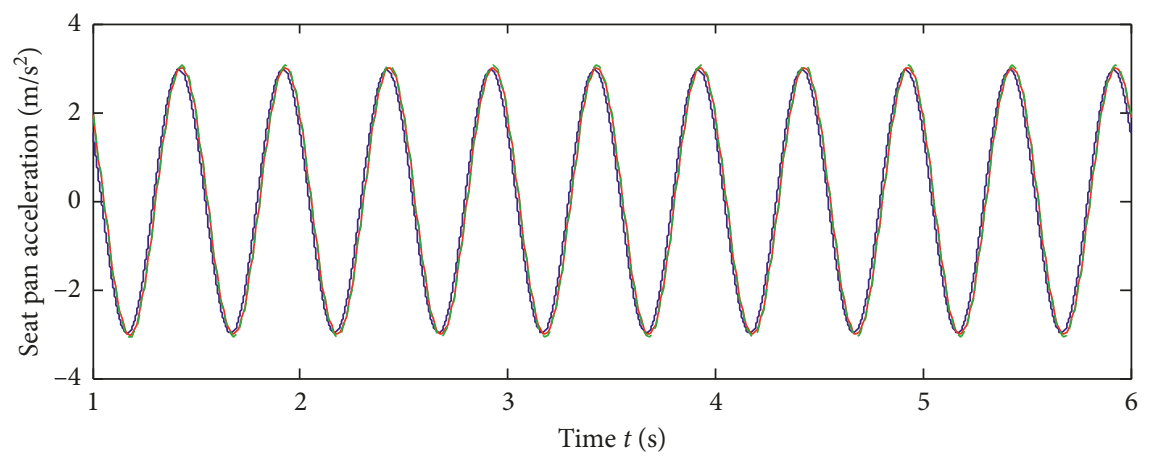

(b)

FiguRE 5: A comparison of the seat pan acceleration responses among the tested data (---), the simplified model (-), and the complex model (-) of the seat system under harmonic excitations with the excitation frequency (a) $f=1.0 \mathrm{~Hz}$ and (b) $f=2.0 \mathrm{~Hz}$.

\section{Influence Analysis of Kinematic Parameters on $\rho_{k}, \rho_{c}, K_{\mathrm{e}}$, and $C_{\mathrm{e}}$}

In this section, the influence laws of kinematic parameters on the stiffness transformation coefficient $\rho_{k}$, the damping transformation coefficient $\rho_{c}$, the equivalent stiffness $K_{\mathrm{e}}$, and the equivalent damping $C_{\mathrm{e}}$ were revealed on the basis of the values for the seat system in Table 2 .

The influences of the kinematic parameters $a$ and $c$ on the stiffness transformation coefficient $\rho_{k}$ and the equivalent stiffness $K_{\mathrm{e}}$ are shown in Figure 6 and Figure 7, respectively. The influences of the kinematic parameters $a$ and $c$ on the damping transformation coefficient $\rho_{c}$ and the equivalent damping $C_{e}$ are shown in Figure 8 and Figure 9, respectively.

Figure 6(a) shows that the stiffness transformation coefficient $\rho_{k}$ approximately linearly increases with the increase of the suspension deformation $u$. Moreover, with the increase of the kinematic parameters $a$, the stiffness transformation coefficient $\rho_{k}$ decreases. Figure 6(b) depicts the same rules of the kinematic parameters $a$ and $c$ on the equivalent stiffness $K_{\mathrm{e}}$. Figure 7 further illustrates the above rules. From Figure 8, it can be seen that the damping transformation coefficient $\rho_{c}$ also approximately linearly increases with the increase of the suspension deformation $u$. The larger the values of the kinematic parameters $a$ and $c$ are, the smaller the value of the damping transformation coefficient $\rho_{c}$ is. Similar change characteristics are also observed to occur in Figure 9.

\section{Conclusions}

For the seat suspension system, the development and implementation of most of the control strategies depend on its dynamic model. The primary motivation of this paper is to create a simple seat model with reasonable accuracy. Thus, a simplified analytical model with transformation coefficients of seat suspension with a complex scissor mechanism for control strategies development is proposed. Firstly, the analytical formulae of the equivalent stiffness $K_{\mathrm{e}}$ and the stiffness transformation coefficient $\rho_{k}$ were deduced. The analytical formulae of the equivalent damping coefficient $C_{\mathrm{e}}$ and the damping transformation coefficient $\rho_{c}$ were also deduced. Then, the motion equation of the simplified model was created. Secondly, the nonlinear dynamic equation of a complex seat model including the kinematic characteristics is established. Finally, the simplified model was validated by the tested data and compared with the complex model and the tested data. Moreover, the influence laws of kinematic parameters on $\rho_{k}$ and $\rho_{c}$ were revealed.

(1) Through the accuracy verification of random vibration response, it can be seen that the accuracy of the simplified model can satisfy the control strategies realization in practical engineering. (2) By comparison of the vibration transmissibility, the results show that the transmissibility curve calculated from the simplified model can reflect the real transmission characteristics of the seat suspension system. (3) By comparison of harmonic response, the results show that the simplified model can be considered suitable 


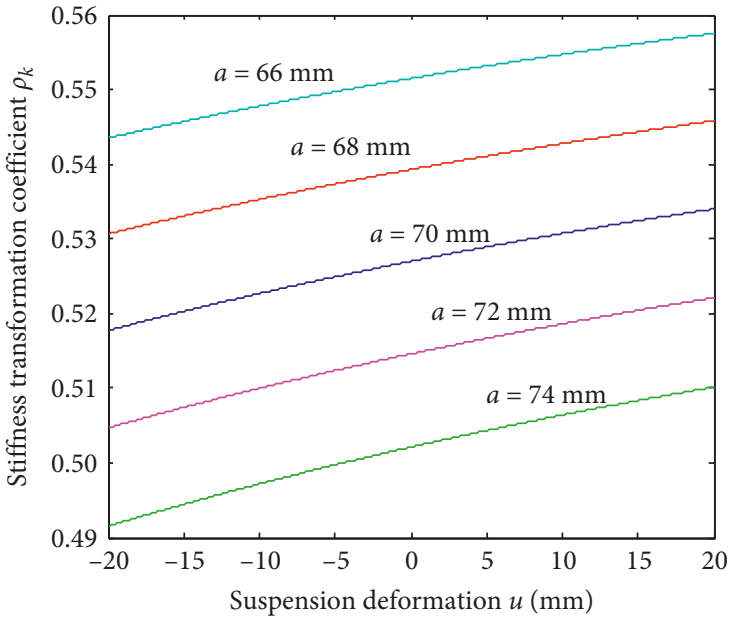

(a)

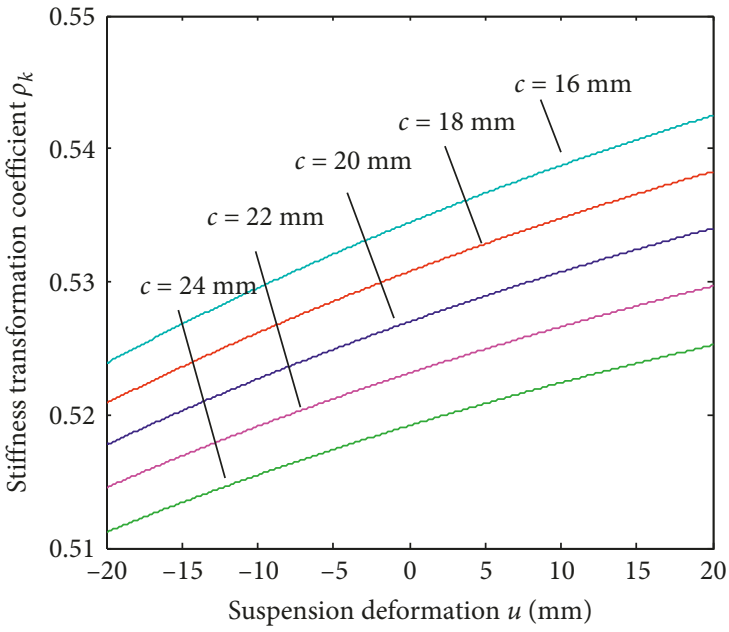

(b)

FiguRE 6: The stiffness transformation coefficient $\rho_{k}$ versus the suspension deformation $u$ : (a) at different values of the kinematic parameter $a$ and (b) at different values of the kinematic parameter $c$.

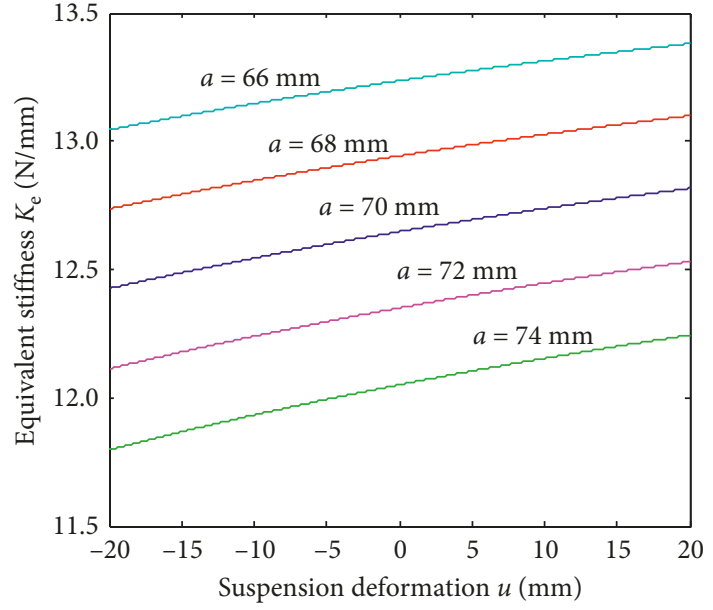

(a)

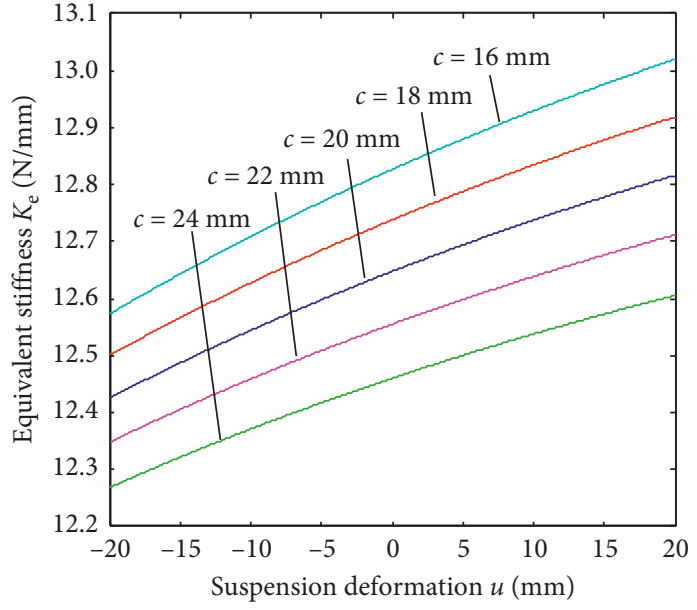

(b)

Figure 7: The equivalent stiffness $K_{\mathrm{e}}$ versus the suspension deformation $u$ : (a) at different values of the kinematic parameter $a$ and (b) at different values of the kinematic parameter $c$.

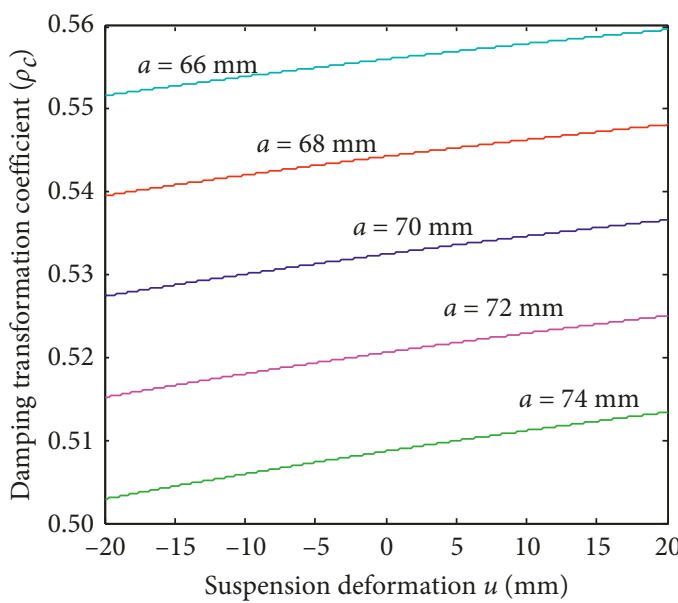

(a)

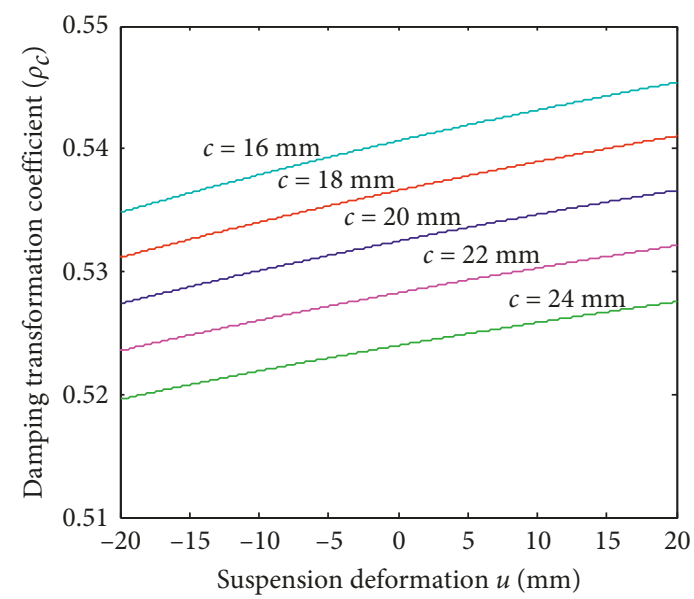

(b)

FIGURE 8: The damping transformation coefficient $\rho_{c}$ versus the suspension deformation $u$ : (a) at different values of the kinematic parameter $a$ and (b) at different values of the kinematic parameter $c$. 


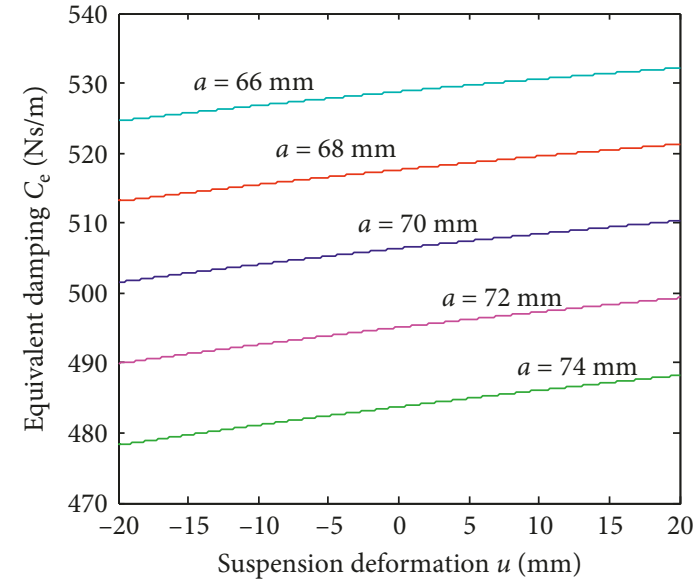

(a)

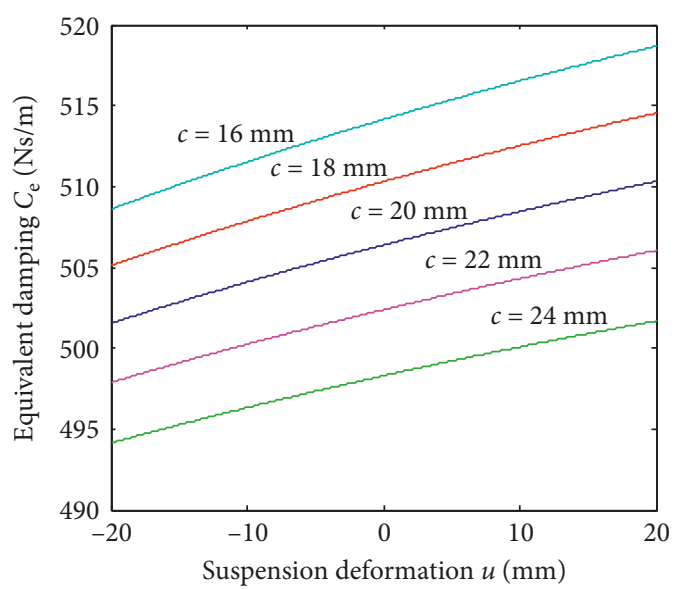

(b)

Figure 9: The equivalent damping $C_{\mathrm{e}}$ versus the suspension deformation $u$ : (a) at different values of the kinematic parameter $a$ and (b) at different values of the kinematic parameter $c$.

for reproducing the real seat acceleration response. (4) Both the stiffness transformation coefficient $\rho_{k}$ and the damping transformation coefficient $\rho_{c}$ approximately linearly increase with the increase of the suspension deformation $u$. With the increase of the kinematic parameters $a$ and $c$, both $\rho_{k}$ and $\rho_{c}$ decrease.

The proposed model provides an accurate and efficient tool for designing controllable seat suspension system that minimizes a necessary tuning process. In the following study, the nonlinear stiffness transformation and the asymmetric damping transformation would be an interesting topic about getting reasonable simple models for control strategies development.

\section{Data Availability}

The data used to support the findings of this study are available from the corresponding author upon request.

\section{Conflicts of Interest}

The authors declare no conflicts of interest.

\section{Acknowledgments}

This study was supported by the National Natural Science Foundation of China (51575325) and BUPT Excellent Ph.D. Students Foundation (CX2016206).

\section{References}

[1] B. B. Du, P. L. Bigelow, R. P. Wells, P. Hall, and H. W. Davies, "The impact of different seats and whole-body vibration exposures on truck driver vigilance and discomfort," Ergonomics, vol. 61, no. 4, pp. 528-537, 2018.

[2] N. Raffler, J. Rissler, R. Ellegast, C. Schikowsky, and T. Kraus, "Combined exposures of whole-body vibration and awkward posture: a cross sectional investigation among occupational drivers by means of simultaneous field measurements," Ergonomics, vol. 60, no. 11, pp. 1-12, 2017.

[3] L. L. Zhao, C. C. Zhou, Y. W. Yu, and F. X. Yang, "Hybrid modelling and damping collaborative optimisation of Fivesuspensions for coupling driver-seat-cab system," Vehicle System Dynamics, vol. 54, no. 5, pp. 667-688, 2016.

[4] F. Diba and E. Esmailzadeh, "Development of hybrid electric heavy-duty truck with self-propelled trailer," International Journal of Heavy Vehicle Systems, vol. 25, no. 2, pp. 203-222, 2018.

[5] G. Wang, K. Li, J. Yang, and C. Liang, "Simulation and vibration isolation optimization on the cab mount of a commercial vehicle," Automotive Engineering, vol. 39, pp. 1081-1086, 2017.

[6] A. Gupta and V. Rastogi, "Computational modelling and simulation of commercial truck with road-tyre interactions to evaluate ride comfort," International Journal of Heavy Vehicle Systems, vol. 25, no. 2, p. 133, 2018.

[7] X. Wang, F. Bi, and H. Du, "Reduction of low frequency vibration of truck driver and seating system through system parameter identification, sensitivity analysis and active control," Mechanical Systems and Signal Processing, vol. 105, pp. 16-35, 2018.

[8] F. X. Yang, L. L. Zhao, Y. W. Yu, and C. C. Zhou, "Analytical description of ride comfort and optimal damping of cushionsuspension for wheel-drive electric vehicles," International Journal of Automotive Technology, vol. 18, pp. 1121-1129, 2017.

[9] L. L. Zhao, Y. W. Yu, C. C. Zhou, and S. Mao, "Test verification of a seat-cabin system vertical dynamic model for highgrade fork lift trucks," International Journal of Modeling, Simulation, and Scientific Computing, vol. 9, article 1850003, 2018.

[10] L. L. Zhao, Y. W. Yu, and C. C. Zhou, "Comparative research on optimal damping matching of seat system for an offhighway dump truck," International Journal of Engineering, Transactions B: Applications, vol. 31, no. 2, pp. 204-211, 2018.

[11] D. Ning, S. Sun, H. Du, and W. Li, "Integrated active and semi-active control for seat suspension of a heavy duty vehicle," Journal of Intelligent Material Systems and Structures, vol. 29, pp. 91-100, 2018.

[12] J. E. D. Ekoru, O. T. C. Nyandoro, and T. Chingozha, "An Udwadia-Kalaba Equation based active seat suspension controller for mining dump trucks," IFAC-PapersOnLine, vol. 49, pp. 184-189, 2016.

[13] A. Alfadhli, J. Darling, and A. J. Hillis, "The control of an active seat with vehicle suspension preview information," Journal of Vibration and Control, vol. 24, no. 8, pp. 1412-1426, 2018. 
[14] X. L. Feng and J. Hu, "Numerical optimization of vibration acceleration transmissibility for seat suspension system in vehicles," Journal of Vibroengineering, vol. 18, pp. 1115-1132, 2016.

[15] C. Wang, X. Zhang, K. Guo, J. Lv, and Y. Yang, "Hierarchical optimisation on scissor seat suspension characteristic and structure," Vehicle System Dynamics, vol. 54, no. 11, pp. 1538-1553, 2016.

[16] W. B. Shangguan, Y. Shui, and S. Rakheja, "Kineto-dynamic design optimisation for vehicle-specific seat-suspension systems," Vehicle System Dynamics, vol. 55, no. 11, pp. 1-22, 2017.

[17] L. L. Zhao, C. C. Zhou, and Y. W. Yu, "Identification and optimisation of surrogate model parameters of the bus driver's seat suspension," International Journal of Vehicle Systems Modelling and Testing, vol. 11, no. 4, pp. 330-342, 2016.

[18] D. X. Phu, S. M. Choi, and S. B. Choi, "A new adaptive hybrid controller for vibration control of a vehicle seat suspension featuring MR damper," Journal of Vibration and Control, vol. 23, no. 20, pp. 3392-3413, 2016.

[19] P. X. Do, S. B. Choi, Y. S. Lee, and M. S. Han, "Vibration control of a vehicle's seat suspension featuring a magnetorheological damper based on a new adaptive fuzzy slidingmode controller," Proceedings of the Institution of Mechanical Engineers, Part D: Journal of Automobile Engineering, vol. 230, no. 4, pp. 437-458, 2016.

[20] D. Ning, S. Sun, F. Zhang, H. Du, and W. Li, "Disturbance observer based Takagi-Sugeno fuzzy control for an active seat suspension," Mechanical Systems and Signal Processing, vol. 93, pp. 515-530, 2017.

[21] S. Rajendiran and P. Lakshmi, "Simulation of PID and fuzzy logic controller for integrated seat suspension of a quarter car with driver model for different road profiles," Journal of Mechanical Science and Technology, vol. 30, no. 10, pp. 4565-4570, 2016.

[22] D. Ning, S. Sun, F. Zhang, H. Du, and W. Li, “An active seat suspension design for vibration control of heavy-duty vehicles," Journal of Low Frequency Noise Vibration and Active Control, vol. 35, no. 4, pp. 264-278, 2016.

[23] L. L. Zhao, C. C. Zhou, and Y. W. Yu, "Hybrid modeling of driver's seat-cushion coupled system for metropolitan bus," Journal of Low Frequency Noise, Vibration and Active Control, vol. 36, no. 3, pp. 214-226, 2017.

[24] L. L. Zhao, Y. W. Yu, C. C. Zhou, S. F. Wang, and F. X. Yang, "A new hydraulic semi-active suspension based on road statistical properties and its road identification," Applied Science, vol. 8, no. 5, pp. 1-13, 2018.

[25] R. D. Nandurkar, A. Mohanty, and P. Barath, "Design and simulation of automotive seat height adjuster driving mechanism based on multi-body dynamics," Applied Mechanics and Materials, vol. 592-594, pp. 2282-2286, 2014.

[26] K. Hill and A. Dhingra, "Modeling, analysis and optimization of a scissors linkage seat suspension," Engineering Optimization, vol. 35, no. 4, pp. 341-357, 2003.

[27] W. Zhang and J. Zhao, "Analysis on nonlinear stiffness and vibration isolation performance of scissor-like structure with full types," Nonlinear Dynamics, vol. 86, no. 1, pp. 1-20, 2016.

[28] L. L. Zhao, F. X. Yang, Y. W. Yu et al., "Influence of shock absorber asymmetry on vibration responses of seat-occupant system under impact condition," in Proceedings of International Conference on Modelling, Identification and Control (ICMIC 2017), pp. 394-399, IEEE Xplore, Kunming, China, July 2017. 


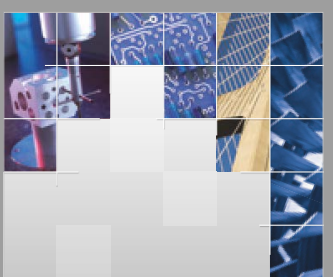

\section{Enfincering}
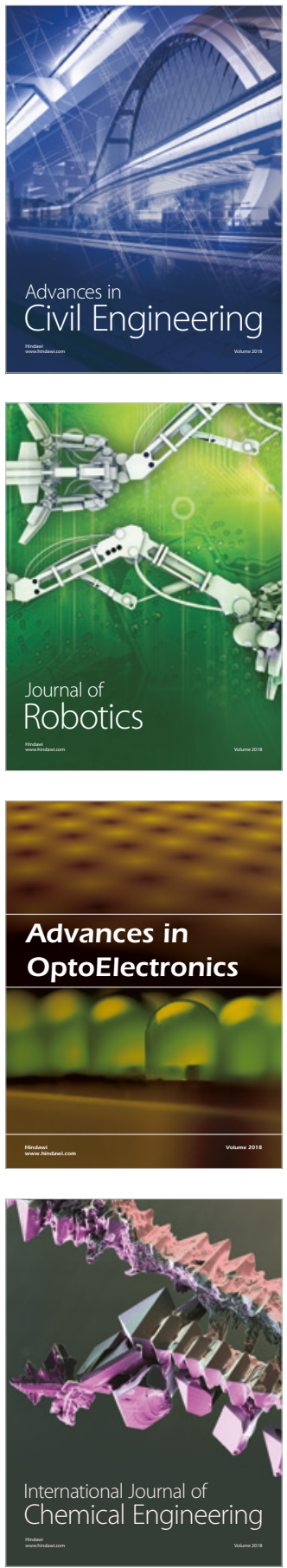

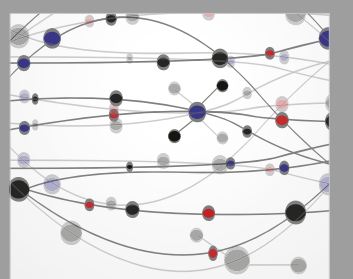

\section{Rotating \\ Machinery}

The Scientific World Journal

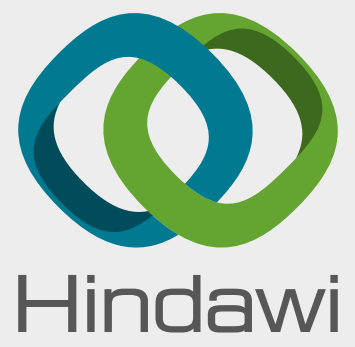

Submit your manuscripts at

www.hindawi.com
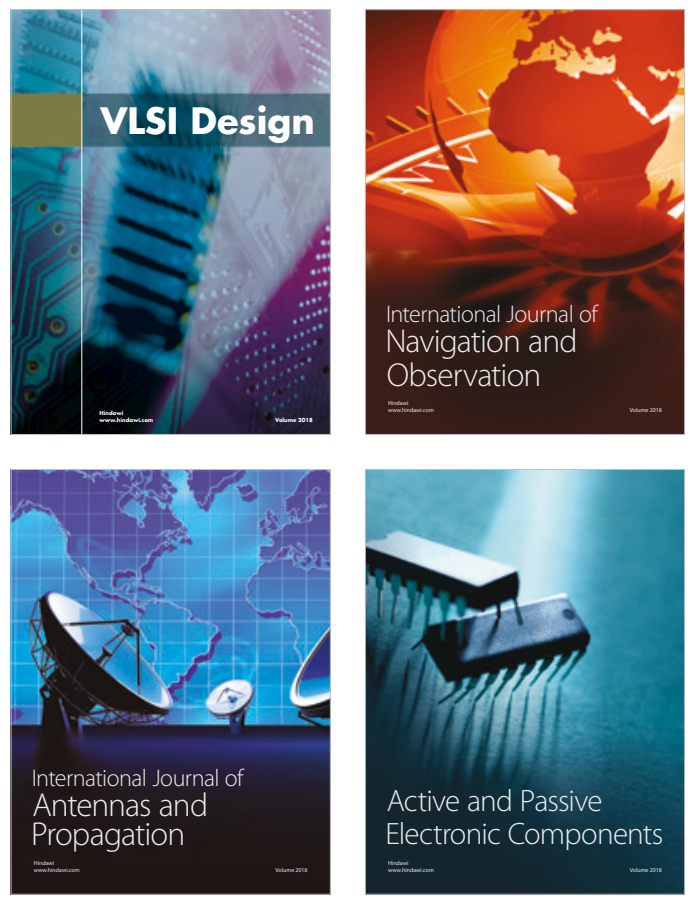
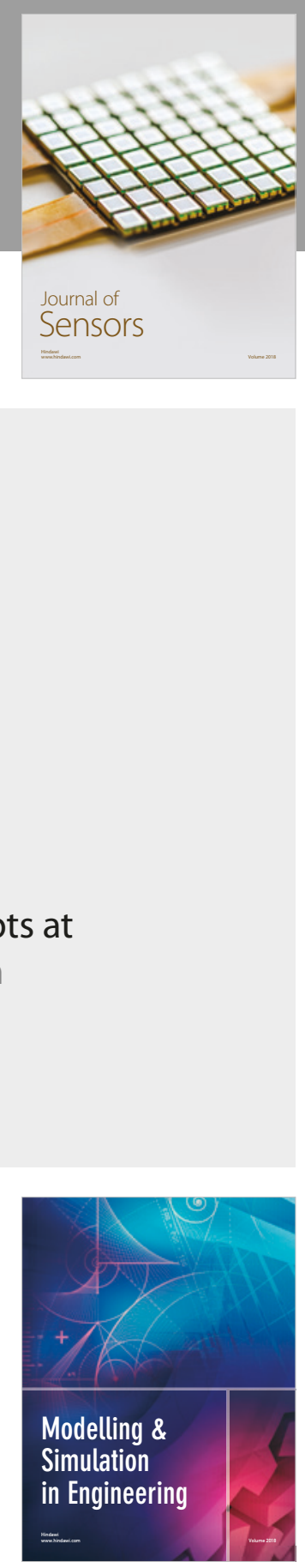

\section{Advances \\ Multimedia}
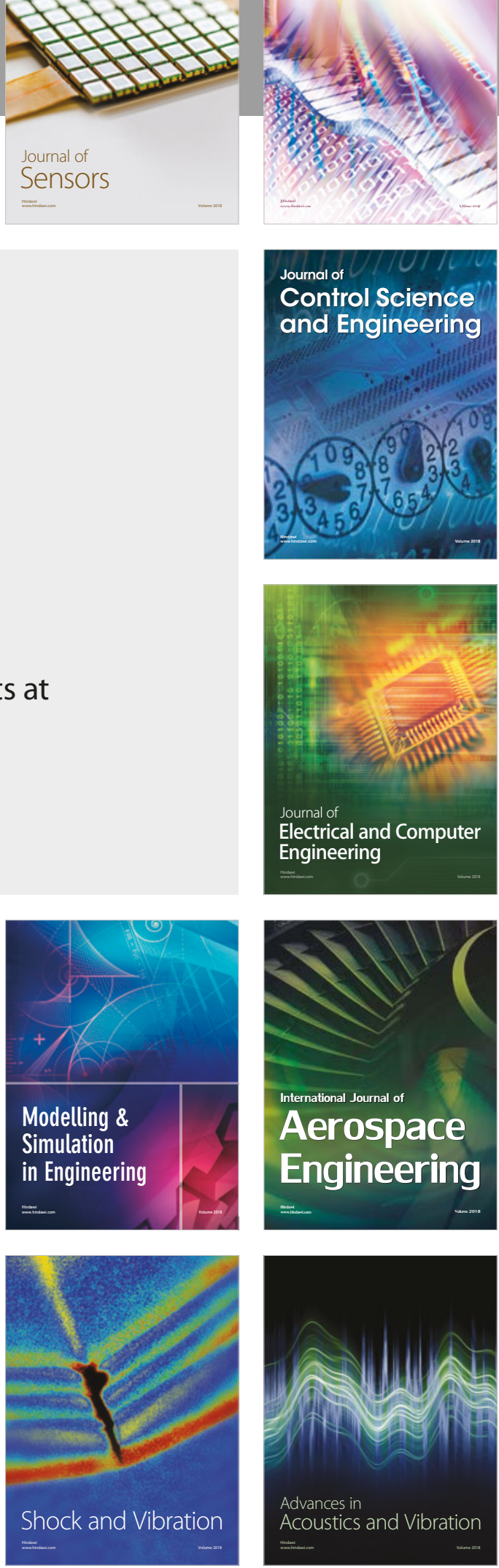